See Article page 200.

\section{Commentary: Looking at the bicuspid aortic valve through the right angle}

\author{
Leonardo A. Mulinari, MD, PhD, and \\ Tomas A. Salerno, MD
}

Repair of a cardiac valve provides superior results compared with replacement. This, however, is only valid for the aortic valve if the repair is perfect, without leakage or creation of stenosis. Although preoperative assessment of the morphology of the aortic valve is very helpful in decision-making for surgery, the functional aspects of the valve are the main determinant as to the long-term durability of the repair. Two-dimensional static imaging may be important in planning the repair, but the breakthrough will likely come when 3-dimensional "real tissue" modeling becomes available.

Nijs and colleagues ${ }^{1}$ in this issue of the Journal conducted an interesting, and potentially (although it is far too early to know) important, study of bicuspid aortic valve (BAV) geometry. This was based on high-resolution computed tomography (CT) angiographic imaging of the chest, used in transcatheter aortic valve implantation protocol. The authors examined BAV morphology, deriving raphe and leaflet angles and commissure positions. Only $50 \%$ of the patients were operated on after CT evaluation, whereas $51 \%$ had no surgery, $24 \%$ had a replacement, and $24 \%$ had a repair. Therefore, only 12 patients would be related to the CT findings, since $50 \%$ of the patients were not operated on.

CT scan images are static, and they only assess structure, rather than function, at a single time point in the cardiac

\footnotetext{
From the Division of Cardiothoracic Surgery, University of Miami Miller School of Medicine and Jackson Memorial Hospital, Miami, Fla.

Disclosures: The authors reported no conflicts of interest.

The Journal policy requires editors and reviewers to disclose conflicts of interest and to decline handling or reviewing manuscripts for which they may have a conflict of interest. The editors and reviewers of this article have no conflicts of interest.

Received for publication Sept 5, 2021; revisions received Sept 5, 2021; accepted for publication Sept 10, 2021; available ahead of print Sept 16, 2021.

Address for reprints: Tomas A. Salerno, MD, Surgery, University of Miami School of Medicine, P. O. Box 016960, JMH-East Tower Room 3072, Miami, FL 33139 (E-mail: tsalerno@med.miami.edu).

JTCVS Techniques 2021;10:216

2666-2507

Copyright (C 2021 The Author(s). Published by Elsevier Inc. on behalf of The American Association for Thoracic Surgery. This is an open access article under the CC BY-NC-ND license (http://creativecommons.org/licenses/by-nc-nd/4.0/).

https://doi.org/10.1016/j.xjtc.2021.09.018
}

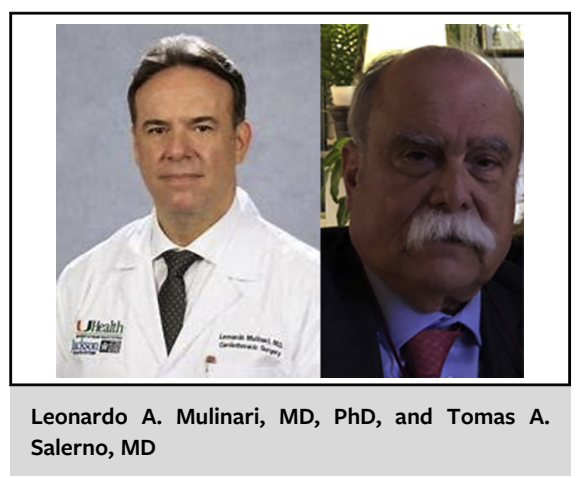

CENTRAL MESSAGE

The search continues for methods to optimize planning for the repair of the bicuspid aortic valve. This study further enhances our knowledge of the anatomy of the bicuspid valve.

cycle. The evaluation of bicuspid aortic valve should include function and structure of the valve at the same time.

Looking ahead in the treatment of patients with BAVs, and perhaps other types of aortic root problems, planning for the procedure will be made simpler, and more precise, with knowledge acquired via anatomical description, as obtained by CT scan. The main question raised by the authors' report is whether data obtained by CT scan would be helpful in the surgical decision-making for BAV repair. Unfortunately, with the limited data provided, this question remains unanswered. Acquisition of preoperative details of the BAV may be helpful in the decision-making, but that doesn't change the clinical criteria for surgery. Furthermore, it would require more patients in the group of valve repair to better correlate with these findings.

\section{Reference}

1. Nijs J, Vangelder B, Tanaka K, Gelsomino S, Van Loo I, La Meir M, et al. Geometric characteristics of bicuspid aortic valves. I Thorac Cardiovasc Surg Tech. 2021;10:200-15. 